\title{
Gender and the Reproductive Rights of Gbagyi Women in North-Central Nigeria
}

\author{
Titilayo Cordelia Orisaremi \\ Department of Sociology and Anthropology, Faculty of Management and Social Sciences, Baze University, Abuja, Nigeria \\ Email: corris76@gmail.com
}

How to cite this paper: Orisaremi, T.C. (2020) Gender and the Reproductive Rights of Gbagyi Women in North-Central Nigeria. Open Access Library Journal, 7: e6797. https://doi.org/10.4236/oalib.1106797

Received: September 7, 2020

Accepted: December 28, 2020

Published: December 31, 2020

Copyright $\odot 2020$ by author(s) and Open Access Library Inc.

This work is licensed under the Creative Commons Attribution International License (CC BY 4.0).

http://creativecommons.org/licenses/by/4.0/

\begin{abstract}
The seeming impervious nature of subsisting gender inequality rooted in resilient patriarchal structures in Nigeria act to deny women access to decision-making on reproductive matters. Respect for women's reproductive rights is crucial to the realization of their reproductive health, yet certain socio-cultural practices hinder the realization of these rights. This qualitative study was aimed at understanding the socio-cultural practices especially gender relations, and their impact on the reproductive rights of Gbagyi women in north-central Nigeria. It investigated gender relations among female and male Gbagyi couples to specifically find out if Gbagyi women: could take a decision on their marital status; could freely choose their spouse or sex partner; could freely discuss and negotiate sex with their spouse/partner; had access to decision making on the number and spacing of children. The study sample was purposively drawn from female and male participants (aged 15 and above) in each of the two selected rural and urban Gbagyi communities. Twenty in-depth interviews and focus group discussions were used to collect data. Results indicated that unequal gender relations in Gbagyi patriarchal setting negatively influenced the perception, acceptance, respect and promotion of women's reproductive rights. The study concluded that Gbagyi women were denied part of their fundamental human rights and therefore recommended prioritizing girl-child education and attitudinal change in Gbagyi women's empowerment.
\end{abstract}

\section{Subject Areas \\ Psychology, Sociology}

\section{Keywords}

Gbagyi Women, Gender Relations, Decision Making, Reproductive Rights, Reproductive Health 


\section{Introduction}

Sub-Saharan Africa has the highest maternal deaths globally with a maternal mortality ratio (MMR) of 546 per 100,000 live births, compared to 12 in countries of developed economies and 187 in the islands of Oceania which is the second highest (United Nations 2017) [1]. Attainment of maternal health remains a major challenge in Nigeria despite being an active participant in the implementation of the global programme on Population and Development; the Millennium Development Goals (MDGs) of 1990-2015; the current Sustainable Development Goals (SDGs) of 2016-2030; and in the efforts of other non-governmental and United Nations agencies. Reduction of the global maternal mortality ratio to less than 70 per 100,000 live births by 2030 is the very first target of the third SDG which also states that no country should have a maternal mortality rate of more than twice the global average by the year 2030 (UNDP 2016) [2].

It is quite embarrassing to note that the $814 \mathrm{MMR}$ estimate for Nigeria at the end of the MDG programme in 2015, increased to 917 by December 2017 (Factbook 2020) [3]. This is about 120 percent more than the target highest global rate of 70, yet we are only a decade away from 2030.

Health has a very broad scope. An essential component of maternal health is sexual and reproductive health. There is an intrinsic relationship between reproductive rights $(\mathrm{RR})$ and reproductive health $(\mathrm{RH})$ and a major challenge to the attainment of RR is unequal gender relations. The MDGs and the SDGs rightly have at least one goal each dedicated to gender equality. Each of these global policy instruments promotes responsible sexuality that permits relations of equity and mutual respect between the genders through the exercise of their RR and responsibilities. Decades after the global efforts at addressing these issues however, certain cultural practices that deny women access to RR and RH information and services which adversely affect maternal outcomes abound. Irrespective of the differences between the various states of northern Nigeria, it is a region of high maternal mortality (Orisaremi \& Alubo 2012 [4]; Izugbara \& Ezeh 2010 [5]; Izugbara et al. 2010 [6]; Makinwa-Adebusoye 2006 [7]; Wall 1998 [8]; Harrison 1997 [9]) relative to the south.

The seeming impervious nature of subsisting gender inequality rooted in resilient patriarchal structures and colonization (Bertolt 2018) [10] act to prevent women from access to and control of scarce resources including decision-making. This subjects them to male control in the public and private spheres including sexuality and reproductive matters, thus jeopardizing women's RR that is crucial to the realization of their RH. These rights include freedom from gender discrimination; modification of customs that discriminate against women; freedom to marry and found a family; and the right to decide the number and spacing of children, etc. (Centre for Reproductive Rights [CRR] 2018) [11].

The Universal Declaration on Human Rights, the African Union Protocol to the African Charter on Human and People's Rights on the Rights of Women in Africa, the Convention on the Elimination of All Forms of Discrimination 
against Women (CEDAW) [12] and the Declaration on the Elimination of Violence against Women [13], constituted the framework for most of the policies of the Nigerian government on women's RR and RH (Orisaremi \& Alubo, 2012) [4]. These instruments underscore the importance of RR in achieving the health and the sustainable development of individual members of every population. In addition to being a signatory to relevant international instruments and treaties, Nigeria developed several national policies aimed at the attainment of the $\mathrm{RH}$ of its citizens especially women and girls (Federal Republic of Nigeria 2001 [14]; 2002 [15]; 2004 [16]; 2007 [17]; 2015 [18]; 2016 [19]).

Implementing these conventions and policy instruments has remained a major test to the nation's sincerity and political will as women's reproductive rights are abused and violated with impunity on a daily basis especially in the face of current Boko Haram insurgence in Nigeria. Despite her recently enacted Violence Against Persons (Prohibition) Act (VAP) 2015, the media is awash with stories of sexual violation of young women and under-aged girls. Harmful traditional practices such as female genital cutting (FGC); involuntary celibacy; forced/early marriage; wife hospitality; unfair divorce regulations persist especially in rural communities.

The role of patriarchy and well established male-centred traditional institutions in these practices cannot be overlooked. Although much caution is needed in comparing cultural practices, the current study was intended to replicate a similar one among the Tarok in the North-Central zone of Nigeria in order to expand the knowledge base of women's RR in northern Nigeria. Similar to the Tarok study, the current study was aimed at understanding socio-cultural practices and gender relations that impact on the RR of Gbagyi women in North-Central Nigeria. It investigated gender relations among the Gbagyi with the specific objective of finding out whether Gbagyi women: can take a decision on their marital status; can freely choose their spouse or sex partner; are free enough to discuss and negotiate sex with their spouse/partner; have access to decision making on the number and spacing of children.

\section{Setting}

Nigeria is occupied by sundry ethnic groups with distinct traditions, customs and languages. The Hausa, Fulani, Igbo and Yoruba are the largest and politically dominant ethnic groups while the north-central zone is characterized by a massive concentration of small ethnic groups of autonomous political systems (Ekanade 1986) [20] which include the Gbagyi. The Federal Republic of Nigeria is divided into thirty-six states and a federal capital territory (FCT); and 774 Local Government Areas (LGAs).

\section{The Gbagyi}

The Gbagyi ethnic group is derogatorily referred to as Gwari by the Hausa (Le Van \& Olubowale 2014) [21]. The Gbagyi are a Nupoid-speaking people predo- 
minantly found in the FCT, Niger and Kaduna states, others are in Nasarawa, Kogi and Kwara states in the north-central geo-political zone of Nigeria. They are found in about thirty LGAs across these states and the FCT. Their major occupation is farming, fishing, pottery and hunting. The Gbagyi are remarkable for the way their women bear heavy loads on their shoulders as distinct from other ethnic groups in Nigeria that traditionally bear weight on the head. This practice is rooted in their respect for the head believed to have a prime place as the "king" of the human body. The men are forbidden by the gods from carrying load. Until their early contact with Islam in the $19^{\text {th }}$ century, and Christian missionaries in the $20^{\text {th }}$ century, the Gbagyi practiced traditional religion, Knunu that was based on their belief in Shekwoyi, a supreme being who created all things (Adedayo \& Sanda 2011) [22].

Two Gbagyi communities, Kwali, the headquarters of Kwali area council in the FCT and Kuchikau in Karu local government area of Nasarawa State constituted the study sites. Although participants' narratives hint at slight differences between the two participant communities: the Gbagyinyamma or Gbagyinkwa in Kwali and the Gbagyingenge in Kuchikau, affirmed that they have the same origin and culture. The entire group is generally referred to as Gwari by Hausa, the dominant language group in northern Nigeria, for reasons obviously connected to phonetics. The Gbagyingenge refers to themselves as "Gbagy" and the Gbagyinkwa as "Gbari". The observable dialectical differences in the language spoken by both largely lie in the use of "r" by the latter and "gy" by the former. For instance, the Gbari would greet "arife" in the morning and the Gbagyi, "agyife". The researcher decided to adopt Gbagyi for both groups because of the larger population of the Gbagingenge while retaining the dialectical differences in participants' narratives. Interestingly, participants from Gbaginyamma (who according to historical sources is the younger group), displayed more knowledge of old traditional marriage practices like nyiugobedawo (expression of interest) and nyipata (engagement) both of which appear to have gone into extinction among the Gbagyingege in Kuchikau.

Certain gender related cultural practices found among the Gbagyi and some ethnic groups in central Nigeria have implications for women's RH. For example, the practice of polygyny, forced marriage, boy child preference, wife labour, gender based violence against women, patrilineage and patriarchy. Patriarchy ensures that authority and decision making in most spheres of life, including health and familial matters, belong to men while their female counterparts are guided by such decisions even at the risk of being denied their RR.

\section{Literature}

In addition to the poor implementation of the nation's landmark policies, the periodic Nigeria NGO Coalition Shadow Report that was presented to the United Nations CEDAW Committee demonstrated the failure of the Nigerian government to adequately reflect the true reality of Nigerian women especially in 
relation to responsibility of the government to protect, promote and fulfill women's rights in Nigeria (Orisaremi 2014b [23]; 2019 [24]).

Marriage is generally regarded as an important social duty to be fulfilled by virtually every individual with little or no alternative among most ethnic groups in Nigeria (Olurode \& Olusanya 1994 [25]; Babatunde 1988 [26]; Smith 2007 [27]). Uchendu (1965) [28] identified the central place of marriage; of starting a family; and in evaluating the worth and maturity of every Igbo man and woman. He observed that the young Igbo girl's life is essentially a preparation for marriage because:

She knows that her great objective in life is marriage; that a woman's glory is her children, in that to have children she must have a husband. This is a chance she cannot afford to miss (p. 53).

Although, the above observation was made decades ago, this holds true for certain traditional and rural communities in Nigeria. Bertolt (2018) [10] examined how colonization subjugated women both in colonial and in contemporary Africa. Situating their study within Walby's (1990) [29] theory of patriarchal structures, Ntoimo and Isuigo-Abanihe (2013) [30] demonstrated how men control women's sexuality and restrict their personal marital choices in Nigeria.

The literature identified the practice of arranged marriage which sometimes includes giving away very young girls to elderly men out of poverty or friendship; women's sub-alternate status; domestic and spousal violence; high bride wealth; the use of women essentially as farm tools Orisaremi 2014a [31]; Bhatta 2014 [32]; Orisaremi \& Alubo 2012 [4]; Ityavar \& Jalingo 2006 [33]; Makinwa-Adebusoye 2006 [7]) as harmful practices that negatively affect women's RR and RH. Galam (1991) [34] noted the denial of brides' consent in some forms of socially recognized traditional Tarok marriages. Scholars have also documented the significance of procreation in marriage in most Nigerian ethnic groups (Fazing 1991 [35]; Smith 2007 [27]; Ityavar \& Jalingo 2006 [33]; Izugbara \& Ezeh 2010 [5]); the effect of gender preference on fertility (Rai et al. 2014) [36]; as well as the import of childlessness in the practice of multiple sex partnerships (Ityavar \& Jalingo 2006 [33]; Orisaremi \& Alubo 2012 [4]) with all its health implications.

Although, Amadiume (1987) [37] depicted the practice of woman-to-woman marriage as a measure of African women's power and wealth, it would appear to be an expression of childless women's desperation to sustain patrilineage and be recognised as women since marriage and motherhood define women's identity in most ethnic groups in Nigeria (Oputa 1987 [38]; Muhammed 1989 [39]). Woman-to-woman marriage is an abuse of the RR of a "female wife", and harmful to her sexual and reproductive health as it denies her the choice of a sex partner/spouse, and exposes her to forced multiple sexual partnerships.

Furthermore, there are cases of women procuring abortion (Arambepola \& Rajapaksa 2014 [40]; Orisaremi 2012b [41]) or committing suicide out of frustration on account of their powerlessness especially in relation to rape, yet, the crime continues unabated (Orisaremi \& Odinkalu 2016 [42]). The British Coun- 
cil's (2013) [43] report on gender in Nigeria affirmed the existence of an entrenched culture of impunity for rape offenders. Besides, experts argued that the relevant formal agencies in Nigeria failed to give desired attention and priority to marital rape and that both the criminal and penal codes exclude it from their respective definition of rape. Thus, the crime assumes different definitions depending on existing justice systems (Orisaremi \& Odinkalu 2016) [42]. This problem was largely addressed by the VAP Act of 2015 . However, there is a general lack of awareness of the VAP 2015 designed to comprehensively address all issues of violence against all persons irrespective of gender, age, and marital status. Also, it is yet to be domesticated in most states of the federation.

Persistence of group norms that attribute dominance in sexual matters to men; and fear of repercussion that inhibits women's ability to negotiate safe sex with their economically dominant male partners (Ezumah 2003) [44], were found to be responsible for women's preference for secret methods of family planning (FP) among a significant number of women in Plateau State, Nigeria (Alubo 2007) [45]. Women's poor access to reproductive decision-making in a highly patriarchal and pronatalist society is not only largely responsible for their choice of concealable FP methods (Akinrinola 1995 [46]; Bankole \& Singh 1999 [47]; Lakew et al. 2013 [48]; Samandary et al. 2010 [49]; Mboane \& Bhatta 2015 [50]) but also for their poor reproductive and sexual health seeking behaviour (Orisaremi 2014b [23]).

Aniekwu (2002) [51] maintained that socio-cultural factors including gender inequality, increase women's susceptibility to HIV infection in Nigeria. Similarly, several studies have underscored the importance of spousal communication in FP uptake (Bawah 2002 [52]; Shattuck et al. 2011 [53]; Mohammed et 2014 [54]); highlighted the negative effects of forced early marriage of girls and wide spousal age gaps on inter-spousal communication (Ityavar \& Jalingo 2006 [33]; Makinwa-Adebusoye 2006 [7]). Their inability to negotiate safe sex with their older and polygynous male spouse implies their vulnerability to sexually transmitted infections (STIs). Closely related to this is the inability of women in some societies to confront, challenge, or control, their husbands' extramarital sexual behaviour (Bhatta 2014 [32]; Smith 2007 [27]). Correspondingly, Pittin (1989) [55] argued that the consent rule hitherto required for access to FP services in Nigeria was highly inequitable as it gave more control to the men who took the decisions while women took the consequences. Schuler et al. (2011) [56] underscored the need to encourage equitable participation of men and women in FP decision making.

Gender shapes sexuality. In order to provide a context for the analysis of gender and RR, we adopt Dixon-Mueller's (1996) [57] gender-sexuality framework which offers a socio-cultural explanation of sexuality and shows how it is socially structured along gender lines and how social agents actively construct the notion of gender and sexuality "in hierarchical social relationships" (p. 139). Thus, gender-sexuality framework grounds gender differences in the social or- 
ganization of a society and explains the different components of sexual behaviours, attitudes, and gender related power dynamics (Orisaremi 2012b) [41]. It shows how men's control over the various dimensions of sexuality increases women's defencelessness in the face of RR abuses and violations. The four interconnected aspects of sexuality identified by the model are: 1) sexual partnerships; 2) sexual acts; 3) sexual meanings; and 4) individual's level of sexual drive and enjoyment. In her analysis, each of these reflects the double standard that exists in human societies as well as the imbalance in the structure, ideology, and access to power and resources, all of which render women incapable of determining their sexual and reproductive lives (Connell 1987 [58]; Orisaremi 2012b [41]). Our focus in this study however excludes the second aspect: sexual acts. The model provides for a link between gender relations and RR in providing a socio-cultural explanation of the level of women's RR attainment in any society.

\section{Methods}

A mixed method design was used for the study: qualitative research enabled an insightful understanding of the complex nature of gender relations and the intricate patterns of social interactions involved in reproductive rights matters; and quantitative method was used to generate the needed socio-demographic data for a descriptive analysis of the study participants. Qualitative tools were handy in clarifying certain ambiguities observed in the course of the research by providing for an understanding of the necessary local knowledge needed to formulate valid and meaningful sociological explanations of data. Thus, the mixed method helped to provide the much needed background picture for a clearer understanding of findings. Also the combination of IDIs and FGDs enriched the data. While IDIs generated in-depth data from individual opinion leaders and key stakeholders, FGDs provided a platform for the researcher to experience and record the dominant, diverse, and even sometimes contradictory opinions expressed by the participating community members interacting in the focus groups.

Data were collected from both rural and urban Gbagyi communities. This was to ensure that findings on the traditional socio-cultural practices that form the subject of this research reflect and are discussed within the context of social change and continuity. The study population from which sample was drawn is female and male indigenes of each of the selected communities aged 15 and above with a good knowledge of the social norms and practices of the community especially in relation to the issues canvassed. Verbal consent was got from each adult participant and from the parents of the FGD participants aged 15 - 18 as appropriate.

Four key community members: the traditional leader, a religious leader, a female opinion leader, and a senior health service provider were the IDI participants. This is because of their strategic positions and the relevance of their roles in the respective communities to the research. Two of them (one in charge of a 
major public health facility, and another, the head of a large religious congregation) were non-indigenes. They had however resided in the participating communities for at least three years respectively and had sufficient knowledge of the social and cultural lives of their host communities. Preliminary visits were made to the two selected communities by the researcher during which she made appropriate contacts with the community leaders and other relevant stakeholders who assisted in identifying suitable potential study participants for both the IDIs and the FGDs. Using a purposive sampling scheme, she also met with individual would-be IDI and FGD participants to inform them of her mission; how important their views were to the exercise; and to find out their willingness to be part of the research.

A total of twelve FGDs and eight IDIs were conducted in both communities. Youth groups (male and female, married and unmarried), some of whom are sexually active were included to enrich the data and bring out some intergenerational differences in opinions. The socio-demographic characteristics and the distribution of the twelve FGDs and eight IDIs are presented in Table 1.

Two local female and male Christian and Muslim field research assistants who understood and spoke Gbagyi, Hausa and English languages fluently, with tertiary education, were recruited from each of the two participating communities. Each group was trained on the research objective, instruments and the needed skills for both quantitative and qualitative data gathering by the principal researcher herself to enhance the quality of data. Training was conducted a day before the actual field exercise in each of the two communities.

Data from the structured questionnaires were analysed electronically and used to describe the socio-demographic background of the participants while qualitative content analysis began with a manual verbatim transcription of audio recorder. The transcripts were translated into English language at the research site and within twenty-four hours. This enabled the researcher and the assistants to seek further clarification of any unclear points or opinions from participants. Thereafter, majority versus minority views, peculiarities, and dissenting voices were identified and compared between the various categories in order to build a unified system and organise the findings presented below.

Administered questionnaires generated the necessary socio-demographic information on each of the participants. Nonetheless, background data for FGD participants is summarized to reflect the constitution of each group as presented in Table 1.

\section{Results}

Although IDIs and FGDs generated qualitative data that explained why gender differences are insignificant in influencing choice of marital status, data equally indicated the importance of gender relations in Gbagyi women's: choice of spouse or sex partner; ability to negotiate sex; and ability to exercise their reproductive rights. These findings are presented below. 
Table 1. Social background of IDI and FGD participants.

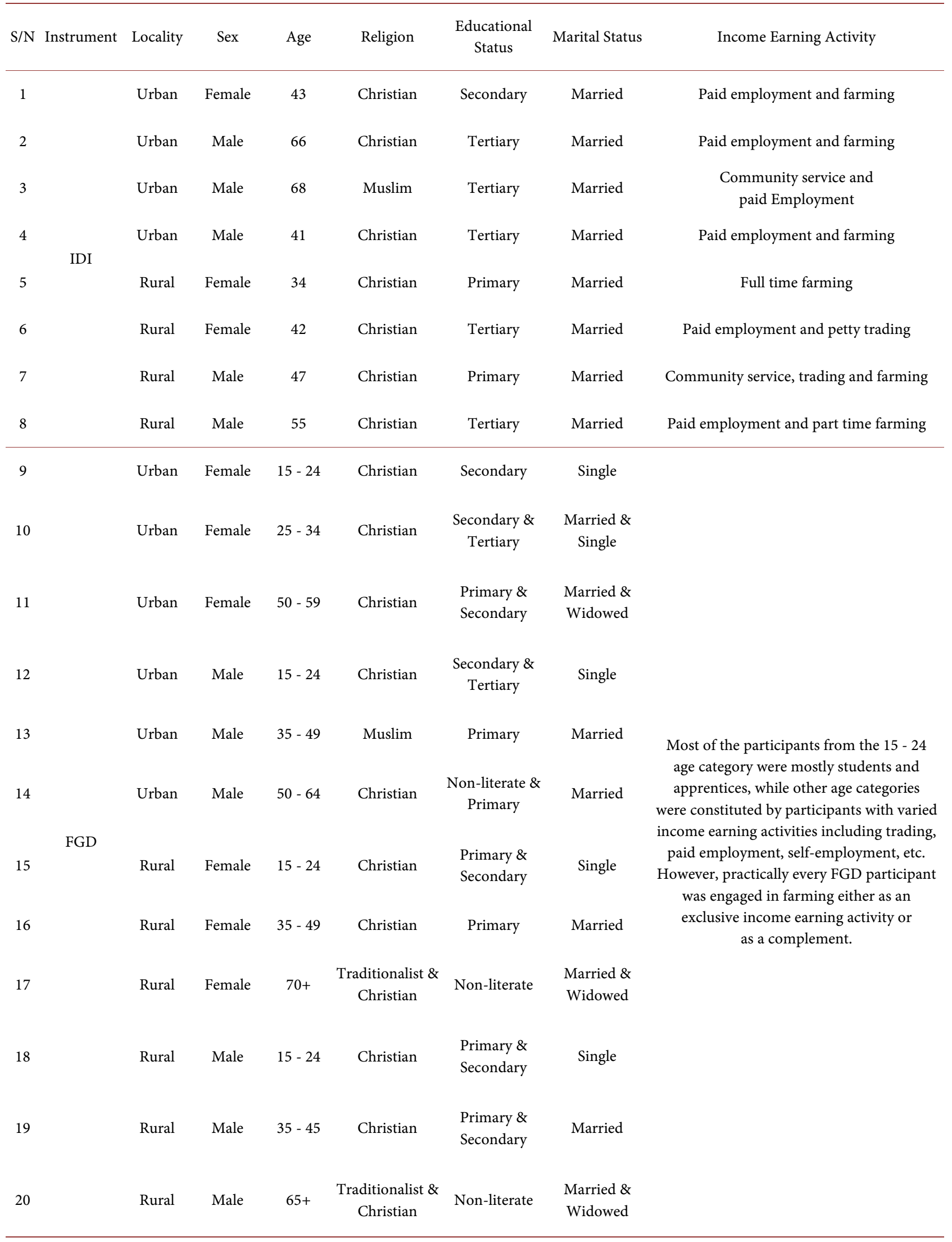




\subsection{Choice of Marital Status}

Marriage is a highly held expectation of every Gbagyi man and woman. The traditional Gbagyi society and culture do not offer its citizens the choice to marry or not. It is a collective expectation and practice. Upon attainment of an age considered marriageable, it is imperative for everyone to marry and start a new family. This is still a predominant view that cuts across all age and gender categories. The question of marital choice even though put differently to various participants, was generally perceived as strange if not weird. The current practice where a few marriageable young women and men remain single was seen as both foreign and an imposition by the current economic hardship rather than by choice. This view cuts across age and gender as illustrated below:

No. She has to marry. In spite of all the wahala (difficulties) she goes through in marriage, it is still the dream of every Gbagyi woman to get married to a man (FGD, Female, 25 - 34, Urban).

It did not happen in the past and even now, it is not acceptable whether you are a young man or a young woman, it is frowned at. Any Gbagyi man or woman who is not married is seen as a child. If it is a man, his married younger brother will be seen as more responsible than himself in the community or at family meetings. For us Gbagyi, it is abnormal (FGD, Male, $65+$, Rural).

Any woman or man that has chosen not to marry must be mentally disturbed or just not OK (general laughter). (FGD, Male, 15 - 24, Rural).

Another participant added:

Even the so called modern single girls and young men become desperate to get married after some time (FGD, Male, 15 - 24, Rural).

The choice to be single is therefore an aberration and is not encouraged by Gbagyi society even in modern times.

\subsection{Choice of Spouse or Sex Partner}

Asked if girls or women, like their male counterparts, can choose who to marry, the dominant opinion among the elderly and middle aged participants was that it was unheard of in the past. They went on to explain that the most common practice in the past was for one's parents especially the father, to either identify a male suitor or to accept the latter's request on behalf of his daughter. He could even be forced on her:

In the past, parents forced their children to marry people they (the children) didn't like but they normally forced girls not boys (FGD, Male, 65+, Rural).

There is discrimination in the sense that, the girls were often forced to marry... everybody is concerned about everybody so not just the maternal or paternal relations; even the leader of the community can determine the 
relationship (IDI, Male, 68, Urban).

For instance, my mum told me that her parents made her marry my father because he was very hard-working and could farm very well. She said that was the practice then. She said she was simply told one night by her parents "you are going to marry this man because he is hard working and can take care of a woman". She had no choice but to marry him... There was also marriage by proxy; the family sees the girl recommends her to their son living afar and if he likes her that is it (IDI, Female, 42, Rural).

Even sons could hardly choose their female spouse in the past without the approval of their parents especially their dad or other older male members of his patrilineage. It was strongly argued that the practice of going by the choice or approval of parents was a reflection of a good upbringing, respect, obedience and decency on the part of the young women and men. The opinion that it revealed the simplicity of the traditional Gbagyi society was also expressed:

It was not that necessary in the past to ask a girl if she was interested in the man or not because their way of doing things in those days was very simple. Once you spoke to your uncle or dad, they knew how to talk to her family too and she would obey unlike now that things have become complicated (FGD, Male, 50 - 64, Urban).

The younger participants, especially females strongly expressed a contrary opinion: girls can now choose who to marry. The consent of the modern Gbagyi would-be-bride is sought before her suitor is formally recognised by her family:

These days, the man will first approach me and ask me if I love him, if 1 say "yes" I will tell him that if he wants to marry me, he has to arrange to come and know my people. If that happens, after their departure, my dad will call me and inform me about his guest. He will ask me if 1 know them and if I am aware of their visit. If I say "yes", then I will be asked if I love the man. It is only after that, that someone will be sent to give an answer to the man's request (FGD, Female, 15 - 24, Rural).

Even the young men now discuss directly with the girls before getting their parents involved:

No! (In chorus) you don't start with your parents. Now you go straight to the girl and speak your mind by telling her what you need and if she needs you, she will tell you before you tell your parents and before she too tells her parents (FGD, Male, 15 - 24, Rural).

Now girls are allowed to know and choose their husband-to-be because of civilization (FGD, Male, 35 - 49, Urban).

Asked how important parent's approval of a would-be-spouse is to modern Gbagyi youth, the opinion that it was wrong for one to go against their parents' wish in matters of marriage, was quite strong among the young male participants. The girls on the other hand, were largely of the opinion that although 
parents' approval is vital, it is secondary. The consent of the would-be-bride based on her love for the suitor, takes precedence if truly the parents wish their daughters well in marriage. Both opinions are illustrated below:

For many young Gbari men, it is difficult to go against your parents' wish especially your mum. I for instance cannot marry any girl not approved by my mum and my dad but my mum first if she doesn't like her and I am really in love with the girl, I know how to work on my mum to accept her after that then my dad, brothers and friends (FGD, 15 - 24, Male, Urban). It is more important that the girl likes the man because she, not her parents will live with him it is also not good to disrespect your parents because of a man (FGD, Female, 15 - 24, Rural).

Some of the older participants explained that even in the past, some parents sought the consent of their daughters prior to giving them in marriage. This was done through her acceptance or rejection of nyipata (a token usually presented in a little delicately woven raffia palm bag or box offered as a sign of formal engagement to the girl by her suitor). In other words, not all parents forced their daughters to marry the men of their (parents') choice even in the past:

She gives her consent before nyipata is given and accepted. If she later found that she no longer likes him, she can ask her parents to return the nyipata because although taken, it is not consumed but safely kept until after marriage when it is given to the girl (IDI, Male, 41, Urban).

But on the whole many women were asked before nyipata was collected and before they were finally given to their husbands even in the past (FGD, Female, 50 - 59, Urban).

The following are the qualities mentioned by the participants that can influence the choice of a male suitor or the latter's proposal to marry their daughters: hard-work; ability to make his bride comfortable, ownership of a large farm (which implies abundant food); a good and respectable family background; self-respect and patience.

Asked what qualities men look out for in a girl to judge her marriageability, the responses indicated hard work; ability to prepare ejhe (a unique corn meal made with specially prepared highly concentrated acidic liquid [alkaline] extracted from ashes which they call "potash"); ability to identify, cut, gather, and transport good quality wood home for fuel; to take care of a man; and do other feminine house chores.

An important new fact that emerged in the course of discussing choice of spouse was the concept of gbepe which ordinarily refers to bride payment. Gbepe also refers to a practice whereby parents choose wives for their sons at birth. Another new fact is the practice of kuche which indicates how couples involved in premarital pregnancy are treated and how the "sin" against the girl's family is atoned for: the pregnant young woman is compelled to move into the man's residence until delivery; the man is made to provide certain prescribed 
items of value (kuche) to be sacrificed to appease the gods and to cleanse the latter's house as part of his penance:

Kuche is when a man impregnates a woman before he knows her people (that is before introduction/engagement preceding marriage). If that happens, she would move into the boy's house and his family would send an emissary to inform her family that their daughter is with them because she had been put in the family way. They will now tell them what the man should pay to appease the land. It could be a chicken, a dog, local drink, and so on, to sacrifice to the gods to cleanse the girl's house. In modern times, he would be asked for items like soft drinks or so for prayers and cleansing (FGD, Female, 35 - 49, Rural).

Ordinarily, items given in exchange for the bride (bride-wealth) includes about twenty to thirty thousand Naira (N20,000 - 30,000) cash. Some participants however explained that each family is at liberty to fix the amount of cash to be included in the bride wealth.

\subsection{Ability to Discuss and Negotiate Sex with Spouse or Partner}

On the whole, it was strongly expressed that marriage denies Gbagyi women the power to discuss or negotiate sex with their male spouse. A wife's attempt to negotiate or refuse to have sex with her husband (except during: her menstrual period; lactation; serious ailment; or if the husband had charmed her to marry him), was strongly perceived as an abominable act by both female and male participants. Below are examples of how these opinions were expressed:

Eeh! It is inconceivable. It is bad except if she is menstruating or if she is really really sick (FGD, Female, 50 - 59, Urban).

Your wife cannot refuse it. Kar! She cannot say so except if the woman was made to marry you through certain means so when her eyes become open she will refuse (FGD, Male, 35 - 45, Rural).

It is an abomination! She can't! It is an abomination to tell your husband that you cannot do it. Whenever the man wants it he just jumps into her room and does whatever he wants. The only excuse is during her period and the man has to be sure she is in her period (IDI, Male, 68, Urban).

No. Except during breastfeeding otherwise she has no right... He can even assume that she is having an affair if she says "no" (IDI, Male, 55, Rural).

Asked why menstruation could prevent a man from sleeping with his wife, the general response from all participants was that it is rooted in the traditional belief that contact between the male organ and menstrual blood renders a man impotent.

Some of the younger female participants however argued that although against the social norms, modern Gbagyi women have devised various ways of saying "no" to their husbands' sexual advances if they are not in the mood. The following statement illustrates this: 
A woman is not expected to refuse but if I do not want and I know he will not accept I can pretend to be sick. But even if you say you are tired or sick. Some men may insist or some may let go but you know that tomorrow you cannot escape it. So for peace sake whether you want it or not you have to get well and just let him do it the following day so that you can have your peace (general laughter) (FGD, Female, 35 - 49, Rural).

The reasons women gave for this behaviour include: some husbands' excessive demand for sex; husbands' lack of empathy for a woman exhausted from physical work; Gbagyi men's notion that their wives are their beasts of burden; actual sickness; not being in the mood; and a man's refusal to meet his wife's material demands:

Of course, she can, especially when she is sick or too weak. You know Gbari women work very hard from morning till night so sometimes they are tired and the man would not want to understand her. And you know some men would want it every day nonstop. Then he gets angry and starts threatening her (FGD, Female, 25 - 34, Urban).

If the woman is too tired after farm work, housework, kitchen work, and the rest of them, and he comes to disturb you when you want to rest although you have to know that it must lead to fight once you tell him "no". Also if he refuses to give you money for food when you know he has. You too may say "no" to his request (FGD, Female, 35 - 49, Rural).

These women equally added that this is often done with much tact to avoid the wrath of the man. Some of the consequences mentioned by them can be summarized thus: Chongogwu (night fight) or being beaten by the man at night; denial of raw food from the man's ban; marriage of another woman; divorce; report to the elders who would always put the blame on the women; and refusal to pay children's school fees. It was however mentioned, by the younger male participants that rather than negotiate, some young modern Gbagyi women, deny their partners sex at will without any explanation:

Of course yes. It is common now. They just decide to cut you off and feel they do not owe you any explanation (FGD, Male, 35 - 49, Urban).

It is a common practice with so called modern women (FGD, Male, 35 - 45, Rural).

Asked how men react to this, the most common reaction mentioned by young and middle aged men are: physical violence; refusal to eat her meals; threat to marry another wife; threat of a divorce; and hanging out late with friends at night as illustrated by the following responses:

For example, a man was always beating his wife at night and when asked for the cause he retorted: "don't mind the stupid woman, every night she goes to lie down among children making the children uncomfortable so that is why I beat her". (General laughter!) As an adult you know what is happen- 
ing (FGD, Male, 35 - 45, Urban).

Some young urban-based female FGD (15 - 24 years) participants were of the opinion that times have changed and that with education, understanding, and true love, young Gbagyi couples are able to freely discuss sex matters and understand each other better:

It is no longer so. If both of you know each other very well even before marriage, you can explain to him when you do not want it and he will un-

derstand. It is important you understand the man you marry.

Acceptance of the practice of multiple sex partnership among men was rife while practically all the participants clearly stated that wife infidelity is highly prohibited and severely sanctioned. Asked if a wife who is aware of her husband's sexual escapade could use a protective or suggest to him to use a condom with her, the spontaneous reaction from virtually each participant (male and female, old and young), was an expression of shock. For them, it was inconceivable for a wife to say that to her husband. Interestingly, only young women with tertiary education as well as an uneducated female opinion leader (an IDI participant), however said they could nicely express their fears to their husbands when he is in a good mood but not when he is "pressed". It is interesting to note that they said this only after they had first expressed shock at the question. This general reaction was clearly linked to fear of the "wrath of the man":

Ehe! (expressed in chorus) You cannot oh!! Ehe!!! He will not agree. He will tell you he cannot use condom with his wife. If you do not agree, he may beat you up that night and you will be sorry for yourself because no one will interfere in a "night fight" between husband and wife (FGD, Female 50 - 59, Urban).

She will be looking for the wrath of the man. It is wrong because ideally a woman does not have a right to do that except she wants his wrath which can be beating or divorce (FGD, Male, 50 - 64, Urban).

\subsection{Access to Decision Making on Number and Spacing of Children}

Opinions were divided on this issue along gender and age lines. While location (urban or rural) of participants made no significant difference in their responses, education was found to be an important factor in a woman's ability to take part in reproductive decision making especially as it relates to FP. Practically every single participant perceived FP as a modern phenomenon relating exclusively to the woman's physical body. Most women in the past naturally spaced their children through prolonged breastfeeding and postpartum abstinence. Opinions on modern women's access to decision-making as regards the number of children to have and how to space them varied: the stronger opinion expressed was that decision-making within the family is the man's exclusive duty. Some however argued that accessing FP services is a woman's affair; and yet for others, 
such decisions are jointly taken by the couple. These three perspectives are illustrated below:

It's the man's business because the man is the head of the house what has a woman to do with decision making and what have you? Even if you are close to your wife... if you are a man, it's your duty (FGD, Male, 50 - 64, Urban).

Some modern Gbagyi men have no problem with it especially the educated ones. They will even go with their wives to do it. Some even before marriage or soon after, they will discuss with their wives-to-be how many children they want (IDI, Female, 43, Urban).

It's a collective decision (za mu yi shawra) (IDI, Male, 47, Rural).

Very few men allow it. Thankfully the service providers no longer insist on husband's consent like they used to do so you, as a woman can go quietly to get it done without telling him. (FGD, Female 35 - 49, Rural).

On whether the average Gbagyi woman has control over her body, the older participants frowned at the idea. For them, the woman is under the authority of the man:

The woman does not have much choice because she is under the authority of her husband and even in those days, a husband's consent is given before a sick woman received any treatment. If she went without him, the medicine man will not attend to her except in case of extreme emergency (IDI, Male, 66, Urban).

If he refuses family planning, it is better not to do it for the sake of peace, even those women who go on to do it secretly face more problems in the end. Some men will not even look at them anymore, some will reject her food; some will beat her up; others will divorce her or even marry another woman; others will accuse her of being unfaithful (FGD, Female, 50 - 59, Urban).

Also a very common opinion expressed especially by female participants was that Gbagyi men generally like to have many children so they discourage their wives from using FP. These wives however take some stealthy measures to get around it:

In the past you gave birth till when the chapter closed. Now, for some, it is still like that but if you are tired you will secretly go and do family planning without your husband knowing because Gbagyi men like to have many children. Even some women do the local one, you will tell your mother and she will prepare the herbs for you without your husband knowing it (FGD, Female, 35 - 49, Rural).

Those who expressed the opinion that every Gbagyi man had a natural desire to have many children linked it to ownership of large farms in the past. They equally added that even now some Gbagyi men still like to have many children 
and where they do not get the cooperation of their wives they are forced to marry more wives irrespective of their faith. Opinion was strong among participants, old and young, women and men, that women have devised ways of circumventing men's absolute control over their bodies the resultant economic burden. This is exemplified in the separate narratives below:

There is a wife to a friend of mine who is more educated than her husband. She has been secretly using FP... He simply feels God has stopped giving them babies... I asked her and she told me she wants to put her three children in good schools but I cannot tell her husband (IDI, Male, 66, Urban).

They secretly take pills. In fact, I have a sister-in-law, my husband's younger sister who is not educated neither is the husband. They have seven children who they cannot take care of. After the birth of the $7^{\text {th }}$ child ... She and her husband have no job and they can't put their children in a good school. I was annoyed and asked her if she did not know her way to family planning clinic. She said her husband would not agree. I said: "how would he when all he does is to climb on you and that is all. He does not even know how they are fed or sent to school". The poor girl goes to the bush every day to cut firewood for sale. She uses the proceeds to take care of the children. She feeds the husband and children and put them in a public primary school. So I warned her to stop coming to my house to ask for any assistance if she won't stop child birth. She wept and wept. I asked her if she does not hear FP adverts in the hospital whenever she took her children for immunization. She said she did so 1 asked her to go to them and ask for FP service... The husband is not complaining yet because the baby is still very little. Perhaps if she does not become pregnant after weaning the child, then he will raise an alarm and start causing trouble (IDI, Female, 43, Urban).

Asked how Gbagyi men react to this furtive action of women, the general opinion was that it could lead to "fight" between the couple. A minority said such women can be accused of promiscuity; it can cause outright separation or divorce; the men may choose to marry new wives; or to withdraw financial, social and any other support previously enjoyed by the women and their children.

\section{Discussion}

It is worthy of note that findings in this study indicate how the Gbagyi are characterized by a sense of group life rather than individuality, thus making the family, kin-group, or community larger than the individual. Consequently, the issue of women's rights exists only within this larger context of the collective and can therefore, be easily sacrificed for the collective interest of the larger group. No matter how questions were asked, responses were limited to marital context.

Marriage is generally regarded as the foundation for starting a family. In traditional African worldview, procreation and parenthood within socially recognised familial setting, guarantee access to the highly valued norm of ancestor- 
hood with all its spiritual and material benefits (Olurode \& Olusanya 1994) [25]. Therefore, in much of traditional Africa, to be unmarried is to be abnormal as marriage is imperative. This certainly discourages the choice of a single lifestyle as in previous studies on other ethnic groups in Nigeria (Uchendu 1965 [28]; Olurode \& Olusanya 1994 [25]; Babatunde 1988 [26]; Smith 2007 [27]; Fazing 1999 [35]; Orisaremi \& Alubo 2012 [4]). This highly held expectation equally dictates to a large extent, the way parents and the larger society bring up children especially daughters (Uchendu 1965) [28], to make them "marriageable" by ensuring that they exhibit the qualities that make them attractive to prospective grooms as indicated in this research. Findings on the provision of additional labour from daughters-in-law in patriarchal settings characterised by patrilocality and patrilineage agree with Rai et al. (2014) [36]. The observed increase in participation in paid labour and neolocality among young Gbagyi couples calls for an evaluation of the relevance of ownership of large families which previously functioned as an indispensable status symbol in most traditional societies. Traditions die hard and there is no change without continuity. Despite the social changes that characterise most Nigerian societies, the very high value traditionally placed on marriage and procreation is clearly linked to the social pressure on many unmarried young women and men who make very desperate moves just to get "hooked" to partners even against their personal wishes or choices. The pressure is nonetheless more on women out of concern for their determinate reproductive cycle.

Findings on choice of spouse reveal that it is limited mostly to men. Men or their families actually decide on the women they judge suitable and take the initiative to ask for her hand in marriage. Even when participants say that modern girls "can choose" who to marry, the girl's choice as in many societies, is a function of her suitors'. The woman or her family merely chooses to give consent or otherwise to an existing choice. Therefore, not only is the woman's choice limited, it is secondary and dependent on the man's choice as patriarchal norm forbids her from initiating the actual process of choosing a would-be male spouse.

Results indicate that child marriage is not a common practice among the Gbagyi. In general, the culture recognises the importance of the consent of a would-be bride through the traditional practice of nyipata (at least among the Gbagyinyamma). However, there were cases of forced marriages especially in the past and girls or young women were most often the victims as found in previous studies (Ityavar \& Jalingo 2006 [33]; Makinwa-Adebusoye 2006 [7]; Orisaremi \& Alubo 2012 [4]) on northern Nigeria. This is a flagrant violation of their RR and the 2015 VAP Act. Although findings in this study indicate that the choice of parents was informed by their wisdom and concern for the well-being of their daughters, it denies girls the right to choose with whom to spend the rest of their lives. For some female participants, the practice of forced marriage is to a certain extent a key factor in sexual-networking and infidelity, unhappy marriages; poor 
spousal communication; spousal violence; abortion; separation; and outright divorce in modern times (Makinwa-Adebusoye 2006 [7]; Orisaremi \& Alubo 2012 [4]; Orisaremi 2012b [41]; 2014a [31]).

Despite the importance placed on mutual love and consent by acquired Christian and Western values, some young participants as in other cultures, still regard parental consent as important in marriage. There is also a general concern by majority of adult participants about the level of sexual indiscipline among the youth. They decried the level of sexual promiscuity and abuses under the guise of friendship or courtship and their support for the penalties against non-marital pregnancy was palpable among traditionalists and Christians alike.

Results show that sexual negotiation between male and female Gbagyi spouses is inconceivable. Only breastfeeding, menses, and serious ailment, can deny most men sex with their wives. On the whole, wives who do not feel up to the task have to hide under any socially acceptable reasons to avoid the legitimate "wrath" of the man: "night fights" (which connotes forced sex and physical violence); denial of raw food and other vital resources (Ezumah 2003) [44] marriage of a new wife; separation; and divorce. It is generally believed that consent to sex is implied in marriage. Therefore, marital rape was not recognised in most Nigerian societies and until the 2015 VAP Act, wives at the mercy of their male spouse (Pittin 1989) [55]. The crime of gender based sexual violence, is only gradually gaining recognition in some sectors of modern Nigeria. There is an urgent need to have the VAP domesticated and a massive awareness campaign among the general populace. Similar to earlier findings among the Tarok, the norm of postpartum abstinence applies primarily to women. Men are at liberty to continue sexual activities with other women like wives, friends, and so on. This reflects the prevailing double standards in patriarchal societies (Orisaremi 2013) [59].

Data on reproductive decision making clearly demonstrate a link between patriarchal attitudes and female poverty and vulnerability to all forms of STIs as earlier documented (Rai et al. 2014 [36]; Bhatta 2014 [32]; Ityavar \& Jalingo 2006 [33]; Aniekwu 2002 [51]), and between patriarchate and pronatalist choices (OlaOlorun et al. 2016 [60]; Mboane \& Bhatta 2015 [50]; Eliason et al. 2013 [61]; Mohammed et al. 2014 [54]; Lackew et al. 2013 [48]; Shattuck et al. 2011 [53]). Data equally support a strong relationship between women's poor access to decision making and their secret use of FP services (Alubo 2007 [45]; Izugbara \& Ezeh 2010 [5]; Orisaremi \& Alubo 2012 [4]). All of which confirms the theoretical framework for the current study, the Gender-Sexuality framework that links gender relations with reproductive health.

Finally, female education and economic empowerment were shown to be key factors that emboldened women who could risk engaging in secret child spacing. Since such wives can take responsibility for themselves and their children's education they can withstand the consequences of their action if and when their husbands decide to unleash their "wrath". Thus, confirming earlier studies that 
point to a significant relationship between education and wives' contraceptive practices (Rai et al. 2014 [36]; Mohammed et al. 2014 [54]; Ndahindwa et al. $2014[62])$.

\section{Conclusion}

This ethnographic study demonstrates how the cultural practice of unequal gender relations influences the perception of women's RR; the acceptance of these rights; and how they are respected and promoted in a patriarchal setting. Women's RRs are an integral part of their human rights. Therefore, their disadvantaged position and poor access to $R R$, translates to a denial of their fundamental human rights. Despite the reported positive social changes, and the existing instruments that are designed to guarantee women's sexual and $\mathrm{RH}$, Gbagyi women's lot is a far cry from the ideal. Increased access to formal education and economic empowerment are critical tools in creating awareness and achieving desired levels of gender equality. It is therefore imperative that government and all relevant agencies give priority to the education of the girl-child and the implementation of affirmative action in favour of women's access to skill acquisition, credit facilities, paid employment and any other activity that can economically empower them and boost their capacity to actively participate in decision-making especially in matters that concern their physical wellbeing and lives' choices. This will also help to check the high prevalence of violence against women by reducing the economic pressure on men.

\section{Conflicts of Interest}

The authors declare no conflicts of interest regarding the publication of this paper.

\section{References}

[1] Population Division of Economic and Social Affairs Department of the United Nations (2017) Reproductive Health Policies 2017: Data Booklet. ST/ESA/SERA/396, United Nations, New York City.

[2] United Nations Development Programme (2016) Sustainable Development Goals. https://www.undp.org/content/undp/en/home/sustainable-development-goals.html

[3] Central Intelligence Agency (2020) Field Anchor People and Society Maternal Mortality Rate.

https://www.cia.gov/library/publications/the-world-factbook/geos/ni.html\#field-anc hor-people-and-society-maternal-mortality-rate

[4] Orisaremi, T.C. and Alubo, O. (2012) Gender and the Reproductive Rights of Tarok Women in Central Nigeria. African Journal of Reproductive Health, 16, 83-96.

[5] Izugbara, C. and Ezeh, A. (2010) Women and High Fertility in Islamic Northern Nigeria. Studies in Family Planning, 41, 193-204.

[6] Izugbara, C., Ibisomi, L., Ezeh, A. and Mandara, M. (2010) Gendered Interests and Poor Spousal Contraceptive Communication in Islamic Northern Nigeria. BMJ Sexual \& Reproductive Health, 36, 219-224. http://dx.doi.org/10.1783/147118910793048494 
[7] Makinwa-Adebusoye, P. (2006) Hidden: A Profile of Married Adolescents in Northern Nigeria. Action Health Incorporated, Lagos.

[8] Wall, L.L. (1998) Dead Mothers and Injured Wives: The Social Context of Maternal Morbidity and Mortality among the Hausa of Northern Nigeria. Studies in Family Planning, 29, 341-359. https://doi.org/10.2307/172248

[9] Harrison, K.A. (1997) The Importance of the Educated Healthy Woman in Africa. The Lancet, 349, 644-642. https://doi.org/10.1016/S0140-6736(97)02192-2

[10] Bertolt, B. (2018) Thinking Otherwise: Theorizing the Colonial/Modern Gender System in Africa. Sociological Review, 22, 3-17.

[11] Centre for Reproductive Rights (2007) Nigeria: Laws and Policies Affecting Their Reproductive Lives. http://www.reproductiverights.org/africa/nig/html

[12] United Nations (1979) Convention on All Forms of Discrimination against Women (CEDAW). United Nations, New York.

https://www.un.org/womenwatch/daw/cedaw/29sess.htm

[13] United Nations Human Rights Office of the High Commissioner (1993) Declaration on the Elimination of Violence against Women.

https://www.ohchr.org/en/professionalinterest/pages/violenceagainstwomen.aspx

[14] Federal Republic of Nigeria (2001) National Reproductive Health Policy and Strategy to Achieve Quality Reproductive and Sexual Health for All Nigerians. Federal Ministry of Health, Abuja.

[15] Federal Republic of Nigeria (2002) National Policy and Plan of Action on Elimination of Female Genital Mutilation in Nigeria. Federal Ministry of Health, Abuja.

[16] Federal Republic of Nigeria (2004) National Policy on Population for Sustainable Development. National Population Commission, Abuja.

[17] Federal Republic of Nigeria (2007) National Gender Policy 2006. Federal Ministry of Women Affairs and Social Development, Abuja.

[18] Federal Republic of Nigeria (2015) Violence Against Persons Prohibition Act. Enacted by National Assembly, Abuja.

[19] Federal Republic of Nigeria (2016) National Health Policy 2016. Federal Ministry of Health, Abuja.

[20] Ekanade, S. (1986) The Land and Peoples. In: Falola, T. and Adediran, A., Eds., $A$ New History of Nigeria for Colleges Book One (Peoples, States and Culture Before 1800), John West Publications Ltd., Ikeja.

[21] Le Van, A.C. and Olubowale, J. (2014) 'I Am Here Until Development Comes': Displacements, Demolition and Property Rights in Urbanizing Nigeria. African Affairs, 113, 387-408. https://doi.org/10.1093/afraf/adu030

[22] Adedayo, A.K. and Sanda, A.Y.L. (2011) Mystical Powers of Witchcraft among the Gbagyis. Ilorin Journal of Religious Studies, 1, 77-92.

[23] Orisaremi, T.C. (2016) Gender, Sexual Health Seeking Behavior and HIV/AIDS among Tarok Women in North-Central Nigeria. Health Care for Women International, 37, 687-704. https://doi.org/10.1080/07399332.2014.971953

[24] Orisaremi, T.C. (2019) Globalization: Is African Women's Reproductive Health Getting Better or Worse? The Nigerian Experience. International Journal of Research and Innovation in Social Science, 3, 21-27.

https://www.rsisinternational.org/journals/ijriss/Digital-Library/volume-3-issue-1/2 1-27.pdf

[25] Olurode, L. and Olusanya, P.O. (1994) Nigerian Heritage: The Yoruba Example. 
Rebonik Publications Ltd., Lagos.

[26] Babatunde, E.D. (1988) The Family in Contemporary Africa. In: Olusanya, P.O. and Olurode, L., Eds., Readings in Introductory Sociology, John West Publications Ltd., Ikeja, 59-75.

[27] Smith, D.J. (2007) Modern Marriage, Men's Extramarital Sex, and HIV Risk in Southeastern Nigeria. American Journal of Public Health, 97, 997-1005. https://doi.org/10.2105/AJPH.2006.088583

[28] Uchendu, V.C. (1965) The Igbo of South East Nigeria. Holt, Rinehart and Wiston Inc., New York.

[29] Walby, S. (1990) Theorising Patriarchy. Basil Blackwell, Oxford.

[30] Ntoimo, L.F.C. and Isiugo-Abanihe, U. (2013) Patriarchy and Singlehood among Women in Lagos, Nigeria. Journal of Family Issues, 35, 1980-2008.

https://doi.org/10.1177/0192513X13511249 http://jfi.sagepub.com/content/early/2013/11/19/0192513x13511249

[31] Orisaremi, T.C. (2014) Spousal Violence against Women in Nigeria. In: Bassey, R., Alemika, E. and Tamgban, O., Eds., Policing and Crime Prevention in Nigeria. African Council on Narcotics \& Crime Prevention, Jos, 295-329.

[32] Bhatta, D.N. (2014) Shadow of Domestic Violence and Extramarital Sex Cohesive with Spousal Communication among Males in Nepal. Reproductive Health, 11, Article No. 44. https://doi.org/10.1186/1742-4755-11-44

[33] Ityavar, D. and Jalingo, I.B. (2006) The State of Married Adolescents in Northern Nigeria. Action Health Incorporated, Lagos.

[34] Galam, L. (1999) Courtship and Marriage. In: Lannap, A.L., Ed., The Tarok Woman, University Press Limited, Jos, 13-25.

[35] Fazing, V.N. (1991) Taroh Marriage Customs and the Christian Message. Unpublished Bachelor Dissertation, St Augustine's Major Seminary, Jos.

[36] Rai, P., Paudel, I.S., Ghimire, A., Pokharel, P.K., Rijal, R. and Raj Niraula, S. (2014) Effect of Gender Preference on Fertility: Cross-Sectional Study among Women of Tharu Community from Rural Area of Eastern Region of Nepal. Reproductive Health, 11, Article No. 15. https://doi.org/10.1186/1742-4755-11-15 http://www.reproductive-health-journal.com/content/11/1/15

[37] Amadiume, I. (1987) Male Daughters Female Husbands. Zed Books, London.

[38] Oputa, C. (1987) Women and Children as Disempowered Groups. In: Kalu, A., Ed., Women, Children and the Nigerian Law, Federal Ministry of Justice, Lagos.

[39] Muhammed, S. (1989) Women, the Family and Wider Society. In: Imam, A.M., Pittin, R. and Omole, H., Eds., Women and the Family in Nigeria, Council for the Development of Social Science Research in Africa, Dakar, 29-36.

[40] Arambepola, C. and Rajapaksa, L.C. (2014) Decision Making on Unsafe Abortions in Sri Lanka: A Case-Control Study. Reproductive Health, 11, Article No. 91. https://doi.org/10.1186/1742-4755-11-91

[41] Orisaremi, T.C. (2012) An Explorative Study of Abortion among the Tarok in Central Nigeria. African Sociological Review, 16, 61-76.

[42] Orisaremi, T.C. and Odinkalu, C. (2016) Domestic and Sexual Violence. In: Alemika, E.E.O., Ed., Crime and Public Safety in Nigeria, Malthouse Press Ltd. and CLEEN Foundation, Lagos.

[43] British Council Nigeria (2013) Gender in Nigeria Report 2012: Improving the Lives of Girls and Women in Nigeria: Issues, Policies, Action. British Council. 
[44] Ezumah, N.N. (2003) Gender Issues in the Prevention and Control of STIs and HIV/AIDS: Lessons from Awka and Agulu, Anambra State, Nigeria. African Journal of Reproductive Health, 7, 89-99. https://doi.org/10.2307/3583216

[45] Alubo, O. (2007) Culture, Gender and Women's Reproductive Health in Plateau State. United Nations Fund for Population Activities Nigeria/Plateau State Government, Jos.

[46] Akinrinola, B. (1995) Desired Fertility and Fertility Behavior among the Yoruba of Nigeria: A Study of Couple Preferences and Subsequent Fertility. Population Studies, 49, 317-328. https://doi.org/10.1080/0032472031000148536

[47] Bankole, A. and Singh, S. (1999) Couple's Fertility and Contraceptive Decision Making in Developing Countries: Hearing the Man's Voice. International Family Planning Perspectives, 24, 15-24. https://doi.org/10.2307/2991915

[48] Lakew, Y., Reda, A.A., Tamene, H., Benedict, S. and Deribe, K. (2013) Geographical Variation and Factors Influencing Modern Contraceptive Use among Married Women in Ethiopia: Evidence from a National Population Based Survey. Reproductive Health, 10, Article No. 52. https://doi.org/10.1186/1742-4755-10-52

[49] Samandary, G., Speizer, I.S. and O’Connell, K. (2010) Role of Social Support and Parity on Contraceptive Use in Cambodia. International Perspectives on Sexual and Reproductive Health, 36, 122-131. https://doi.org/10.1363/3612210

[50] Mboane, R. and Bhatta, M.P. (2015) Influence of a Husband's Healthcare Decision Making Role on a Woman's Intention to Use Contraceptives among Mozambican Women. Reproductive Health, 12, Article No. 36. https://doi.org/10.1186/s12978-015-0010-2

[51] Aniekwu, N. (2002) Gender and Human Rights Dimensions of HIV/AIDS in Nigeria. African Journal of Reproductive Health, 6, 30-37. https://doi.org/10.2307/3583254

[52] Bawah, A.A. (2002) Spousal Communication and Family Planning Behavior in Navrongo: A Longitudinal Assessment. Studies in Family Planning, 33, 185-194.

[53] Shattuck, D., Kerner, B., Gilles, K., Hartmann, M., Ng'ombe, T. and Guest, G. (2011) Encouraging Contraceptive Uptake by Motivating Men to Communicate about Family Planning: The Malawi Male Motivator Project. American Journal of Public Health, 101, 1089-1095. https://doi.org/10.2105/AJPH.2010.300091

[54] Mohammed, A., Woldeyohannes, D., Feleke, A. and Megabiaw, B. (2014) Determinants of Modern Contraceptive Utilization among Married Women of Reproductive Age Group in North Shoa Zone, Amhara Region, Ethiopia. Reproductive Health, 11, Article No. 13. https://doi.org/10.1186/1742-4755-11-13

[55] Pittin, R. (1989) The Control of Reproduction: Principle and Practice in Nigeria. In: Imam, A., Pittin, R. and Omole, H., Eds., Women and the Family in Nigeria, Council for the Development of Social Science Research in Africa, Dakar, 93-115.

[56] Schuler, S.R., Rottach, E. and Mukiri, P. (2011) Gender Norms and Family Planning Decision-Making in Tanzania: A Qualitative Study. Journal of Public Health in Africa, 2, e25. https://doi.org/10.4081/jphia.2011.e25

[57] Dixon-Mueller, R. (1996) The Sexuality Connection in Reproductive Health. In: Zeidenstein, S. and Moore, K., Eds., Learning about Sexuality: A Practical Beginning, The Population Council, New York, 137-157.

[58] Connell, R. (1987) Theory of Gender and Power. Stanford University Press, Palo Alto.

[59] Orisaremi, T.C. (2013) The Influence of Breastfeeding Beliefs on the Sexual Practic- 
es of the Tarok in North-Central Nigeria. Sexual and Reproductive Healthcare, 4, 153-160. https://doi.org/10.1016/j.srhc.2013.10.005

[60] OlaOlorun, F., Seme, A., Otupiri, E., Ogunjuyigbe, P. and Tsui, A. (2016) Women Fertility Desire and Contraceptive Behaviour in 3 Peri-Urban Communities in Sub-Saharan Africa. Reproductive Health, 13, Article No. 12.

https://doi.org/10.1186/s12978-016-0118-z

[61] Eliason, S., Baiden, F., Quansah-Asare, G., Graham-Hayfron, Y., Bonsu, D., Phillips, J. and Awusabo-Asare, K. (2013) Factors Influencing the Intention of Women in Rural Ghana to Adopt Postpartum Family Planning. Reproductive Health, 10, Article No. 34. https://doi.org/10.1186/1742-4755-10-34

http://www.reproductive-health-journal.com/content/10/1/34

[62] Ndahindwa, V., Kamanzi, C., Semakula, M., Abalikumwe, F., Hedt-Gauthier, B. and Thomson, D.R. (2014) Determinants of Fertility in Rwanda in the Context of a Fertility Transition: A Secondary Analysis of the 2010 Demographic and Health Survey. Reproductive Health, 11, Article No. 87.

https://doi.org/10.1186/1742-4755-11-87 